OPEN ACCESS

Edited by:

Michael Graner,

University of Colorado Denver,

United States

Reviewed by:

Nilufer Yesilot,

Istanbul University, Turkey

Christos G. Savopoulos,

Aristotle University of

Thessaloniki, Greece

*Correspondence:

Ran Meng

ranmeng2011@126.com

Xunming $\mathrm{Ji}$

jixm@ccmu.edu.cn

†These authors share first authorship

Specialty section:

This article was submitted to

Stroke,

a section of the journal

Frontiers in Neurology

Received: 05 January 2021

Accepted: 12 August 2021

Published: 09 September 2021

Citation:

Li M, Pan L, Gao X, Hou J, Meng R and Ji X (2021) Low Diastolic Blood

Pressure Predicts Good Clinical Outcome in Patients With Cerebral

Venous Thrombosis.

Front. Neurol. 12:649573.

doi: 10.3389/fneur.2021.649573

\section{Low Diastolic Blood Pressure Predicts Good Clinical Outcome in Patients With Cerebral Venous Thrombosis}

\author{
Min $\mathrm{Li}^{1,2 \dagger}$, Liqun Pan ${ }^{1 \dagger}$, Xiaogang Gao ${ }^{3}$, Jiaojiao $\mathrm{Hou}^{4}$, Ran Meng ${ }^{1,2 \star}$ and Xunming $\mathrm{Ji}^{2,5 *}$ \\ ${ }^{1}$ Department of Neurology, Xuanwu Hospital, Capital Medical University, Beijing, China, ${ }^{2}$ Beijing Institute for Brain Disorders, \\ Capital Medical University, Beijing, China, ${ }^{3}$ Department of Medicine, Tianjin Huanhu Hospital, Tianjin, China, ${ }^{4}$ Department of \\ Neurology, Rongcheng City People's Hospital, Baoding, China, ${ }^{5}$ Department of Neurosurgery, Xuanwu Hospital, Capital \\ Medical University, Beijing, China
}

Background: Cerebral venous thrombosis (CVT) refers to a stroke subtype characterized by the disturbance of cerebral venous outflow caused by venous thrombosis. Previous studies have reported a range of factors that predict the prognosis of CVT. This study is aimed to find out whether systolic blood pressure (SBP) and diastolic blood pressure (DBP) are suitable as potential indicators of the severity and clinical outcome in CVT patients.

Methods: The CVT patients admitted to Xuanwu Hospital from January 2014 to December 2019 were enrolled. The severity of CVT was assessed by the National Institute of Health Stroke Scale (NIHSS) and intracranial pressure (ICP) at the time of admission. The modified Rankin score (mRS) was assessed at 6 months of follow-up.

Results: One hundred fifty-six CVT patients were enrolled with a mean age of $35.8 \pm$ 12.8 years. A percentage of 55.8\% of the CVT patients recruited were female, and $17.3 \%$ were either pregnant or in perinatal period. Headache was the most common symptom. SBP and DBP were not correlated with NIHSS at admission. Furthermore, SBP and DBP had no impact on the disturbance of consciousness, epilepsy, intracranial hemorrhage, and mental disorders. However, SBP and DBP were positively correlated with ICP at admission. SBP > $129.5 \mathrm{mmHg}$ and/or DBP $>77.5 \mathrm{mmHg}$ suggested the presence of intracranial hypertension $(I H)$. Based on current results, SBP was not correlated with $\mathrm{mRS}$ at 6 months of follow-up. However, DBP was found to be positively correlated with $\mathrm{mRS}$ at 6 months of follow-up. DBP in CVT patients with good prognosis was significantly lower than in those with poor prognosis. DBP $>79.5 \mathrm{mmHg}$ was identified as a cutoff value to predict a poor clinical outcome. A higher $\mathrm{mRS}$ and a higher rate of poor clinical outcome were found in CVT patients with SBP $>146 \mathrm{mmHg}$ or DBP $>79.5 \mathrm{mmHg}$ compared to those with $\mathrm{SBP} \leq 146 \mathrm{mmHg}$ or $\mathrm{DBP} \leq 79.5 \mathrm{mmHg}$.

Conclusion: SBP $>129.5 \mathrm{mmHg}$ and $\mathrm{DBP}>77.5 \mathrm{mmHg}$ suggested the presence of $\mathrm{IH}$ in CVT patients. DBP $>79.5 \mathrm{mmHg}$ predicted a poor clinical outcome.

Keywords: blood pressure, intracranial hypertension, severity, prognosis, cerebral venous thrombosis (CVT) 


\section{INTRODUCTION}

Cerebral venous thrombosis (CVT) refers to a stroke subtype characterized by the cerebral venous outflow disturbance caused by venous thrombosis (1). In recent studies, it has been demonstrated that the incidence of CVT is potentially higher than expected, reaching $1.32-1.57 / 100,000$ people annually (2). The clinical manifestations of CVT are highly unpredictable (2). In severe CVT cases, patients suffered from disturbance of consciousness, new onset of epilepsy, intracranial hemorrhage, and mental disorders $(3,4)$.

It is reported that $13.4 \%$ of CVT patients had poor prognosis (5). Also, a series of studies have revealed that the following factors predicted poor clinical outcome: male, older age, an increase in National Institutes of Health Stroke Scale (NIHSS) $\geq 3$ at admission, bilateral motor signs, malignancy, central nervous system infection, coma, mental disorders, deep cerebral venous thrombosis, hemorrhagic infarcts, and midline shift (5-7).

It is widely recognized that high blood pressure (BP) is a significant risk factor for arterial stroke and an indicator of poor prognosis in arterial stroke patients (8). However, there are few studies focusing on the role of blood pressure in CVT. The aim of this study is to investigate whether systolic blood pressure (SBP) and diastolic blood pressure (DBP) can be applied as potential indicators of severity and clinical outcome for CVT patients.

\section{METHODS}

\section{Subject Recruitment}

The CVT patients admitted to Xuanwu Hospital from January 2014 to December 2019 were enrolled. This prospective study was approved by the Xuanwu Hospital ethnics committee. The inclusion criterion was CVT confirmed by magnetic resonance venography (MRV), computed tomography venography (CTV), digital subtraction angiography (DSA), or high resolutionmagnetic resonance imaging (HR-MRI).

Intracranial pressure (ICP) was detected by measuring CSF pressure with lumbar puncture. An ICP $>250 \mathrm{mmH}_{2} \mathrm{O}$ was considered as intracranial hypertension (IH) (9). In order to evaluate the clinical outcome of CVT, the modified Rankin score (mRS) was assessed at 6 months of follow-up. mRS $\leq 2$ and $\mathrm{mRS}>2$ were treated as good clinical outcome and poor clinical outcome, respectively (10).

\section{Statistical Analysis}

SPSS Version 16.0 (SPSS, Inc., Chicago, IL, USA) was used for all statistical analyses. The continuous data following Gaussian distribution were expressed as mean \pm standard deviation and analyzed with independent $t$-test, while categorical data were expressed as a number (percentage) and processed using chisquare test. Pearson correlation coefficient and linear regression were used to predict the correlation between continuous variables. Logistic regression models were constructed using enter method. The cutoff points were calculated using receiver operating characteristic (ROC) curves. $p<0.05$ was considered statistically significant.
TABLE 1 | Baseline demographic features and clinical characteristics of patients with $\mathrm{CVT}$.

\begin{tabular}{lc}
\hline Characteristics & Enrolled subjects $(\boldsymbol{N}=\mathbf{1 5 6})$ \\
\hline Age (years) & $35.8 \pm 12.8$ \\
Female & $87(55.8 \%)$ \\
Pregnancy or perinatal period & $27(17.3 \%)$ \\
Co-morbid disease & \\
Hypertension & $21(13.5 \%)$ \\
Diabetes mellitus & $7(4.5 \%)$ \\
Hyperlipidemia & $7(4.5 \%)$ \\
Deep venous thrombosis & $4(2.6 \%)$ \\
Pulmonary embolism & $4(2.6 \%)$ \\
Systemic infectious disease & $3(1.9 \%)$ \\
Smoking & $17(10.9 \%)$ \\
Alcohol & $17(10.9 \%)$ \\
Clinical manifestations & \\
Headache & $140(89.7 \%)$ \\
Visual impairment & $31(19.9 \%)$ \\
Tinnitus & $9(5.8 \%)$ \\
Disturbance of consciousness & $33(21.2 \%)$ \\
New-onset epilepsy & $54(34.6 \%)$ \\
Limb weakness & $52(33.3 \%)$ \\
Blood pressure at admission & \\
Systolic pressure (mmHg) & $122.8 \pm 16.7$ \\
Diastolic pressure (mmHg) & $77.6 \pm 10.8$ \\
\hline
\end{tabular}

\section{RESULTS}

\section{Baseline Demographic Features of CVT Patients}

One hundred fifty-six CVT patients were recruited in this study, with a mean age of $35.8 \pm 12.8$ years. There were $87(55.8 \%)$ female patients, and $27(17.3 \%)$ patients were either pregnant or in the perinatal period. Twenty-one (13.5\%) patients had hypertension, $7(4.5 \%)$ had diabetes mellitus, $7(4.5 \%)$ had hyperlipidemia, 4 (2.6\%) had deep venous thrombosis, 4 (2.6\%) had pulmonary embolism, and $3(1.9 \%)$ had systemic infectious diseases. Seventeen (10.9\%) patients had a history of smoking, and $17(10.9 \%)$ patients had a history of alcohol. Headache (89.7\%) was the most frequent symptom, followed by newonset epilepsy (34.6\%), limb weakness (33.3\%), disturbance of consciousness (21.2\%), visual impairment (19.9\%), and tinnitus (5.8\%). The average SBP and DBP were $122.8 \pm 16.7$ and $77.6 \pm$ $10.8 \mathrm{mmHg}$, respectively (Table $\mathbf{1}$ ).

\section{Blood Pressure Correlates With the Severity of CVT}

NIHSS, clinical presentations, and ICP at admission were used to assess the severity of CVT. Our results showed that SBP and DBP were not correlated with NIHSS $(p=0.107 ; p$ $=0.135$, Figures 1A,B). Results from the present study also revealed that SBP and DBP had no impact on the disturbance of consciousness, epilepsy, intracranial hemorrhage, and mental disorders (Table 2). However, both SBP and DBP were positively 

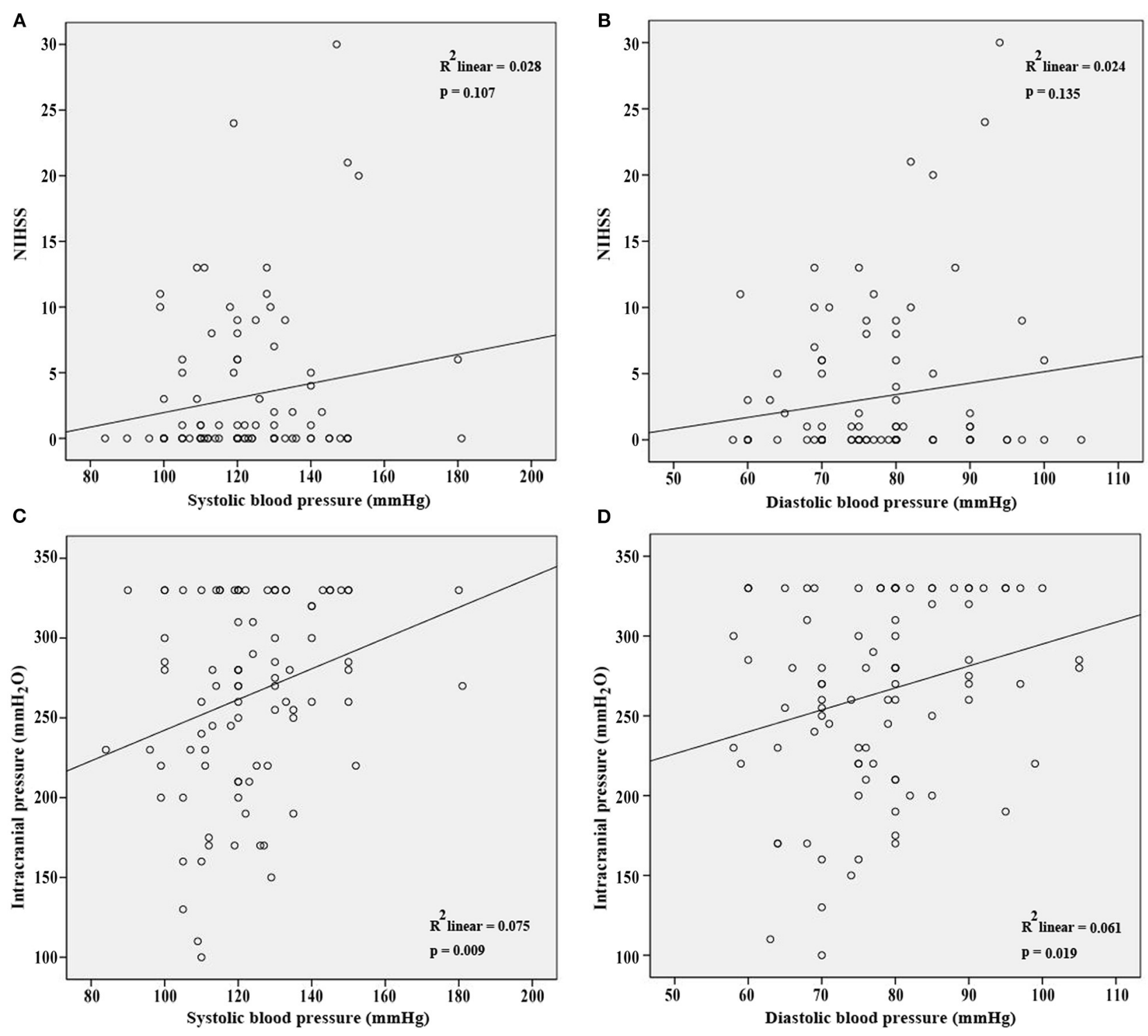

FIGURE 1 | SBP and DBP were not correlated with NIHSS (A,B) at admission. However, SBP and DBP were positively correlated with ICP at admission (C,D)

correlated with ICP $(p=0.009 ; p=0.019$, Figures 1C,D). The ROC curve was used to identify the cutoff values of SBP and DBP. $\mathrm{SBP}>129.5 \mathrm{mmHg}(\mathrm{AUC}=0.7288, p=0.0004$, Figure 2A $)$ and $\mathrm{DBP}>77.5 \mathrm{mmHg}(\mathrm{AUC}=0.6471, p=0.024$, Figure $2 \mathrm{~B})$ were identified as indicators for IH in CVT patients.

\section{DBP Predicts the Prognosis of CVT}

Subsequently, we aimed to evaluate the impact of BP on the prognosis of CVT. SBP was not correlated with mRS at 6 months of follow-up after adjusting for ICP and DBP $(p=0.784 ; p=$ 0.159 , Table 3 ). Notably, DBP was positively correlated with $\mathrm{mRS}$ at 6 months of follow-up after adjusting for ICP and SBP ( $p=$ 0.039, Table 3).

No significant difference was found in SBP between the CVT patients with good prognosis and those with poor prognosis $(p=$
0.222 , Figure 3A). DBP in the subjects with good prognosis was significantly lower compared with those with poor prognosis ( $p$ $=0.046$, Figure 3B). SBP of $146 \mathrm{mmHg}$ and DBP of $79.5 \mathrm{mmHg}$ were identified as the cutoff values (Figures 3C,D). However, SBP $146 \mathrm{mmHg}$ as a cutoff value exhibited low sensitivity and specificity $(\mathrm{AUC}=0.5772, p=0.3830$, Figure $3 \mathrm{C}) . \mathrm{DBP}>79.5$ $\mathrm{mmHg}$ predicted a poor clinical outcome in CVT patients (AUC $=0.6733, p=0.0452$, Figure 3D). CVT patients with $\mathrm{SBP}>$ $146 \mathrm{mmHg}$ or DBP $>79.5 \mathrm{mmHg}$ had significantly higher mRS compared to those with $\mathrm{SBP} \leq 146 \mathrm{mmHg}$ or $\mathrm{DBP} \leq 79.5$ mmHg $(p=0.002, p=0.002$, Figures 3E,F). A higher rate of poor clinical outcome was found in CVT patients with SBP > $146 \mathrm{mmHg}$ or DBP $>79.5 \mathrm{mmHg}$ compared to those with SBP $\leq 146 \mathrm{mmHg}$ or $\mathrm{DBP} \leq 79.5 \mathrm{mmHg}(p=0.008, p=0.005$, Table 4). 


\section{DISCUSSION}

A Turkish multicenter study reported that females are more susceptible to CVT (7). Sixty-eight percent of the CVT patients were female. Results from the present study reported a relatively low proportion of female. Only $55.8 \%$ of the CVT patients were female. Headache was the most frequent symptom based on results from this study. This finding is consistent with the previous reports $(7,11)$. The limitation of this study was the small sample size. For stronger evidence, a multicenter study recruiting CVT patients from 25 tertiary hospitals across China Mainland led by our research team is ongoing (NCT 03919305). Results from this multicenter study will be published later.

Our results also revealed that SBP and DBP were not correlated with NIHSS at admission. However, the results

TABLE 2 | Both SBP and DBP had no impact on disturbance of consciousness, epilepsy, intracranial hemorrhage and mental disorders.

\begin{tabular}{|c|c|c|c|c|c|}
\hline \multirow{2}{*}{$\begin{array}{l}\text { Independent } \\
\text { variables }\end{array}$} & \multirow{2}{*}{$\begin{array}{l}\text { Dependent } \\
\text { variables }\end{array}$} & \multirow[t]{2}{*}{ OR } & \multirow[t]{2}{*}{$P$} & \multicolumn{2}{|c|}{ Confidence interval } \\
\hline & & & & Lower & Upper \\
\hline \multirow[t]{4}{*}{ SBP } & $\begin{array}{l}\text { Conscious } \\
\text { disturbance }\end{array}$ & 0.979 & 0.131 & 0.953 & 1.006 \\
\hline & Epilepsy & 1.013 & 0.266 & 0.990 & 1.036 \\
\hline & $\begin{array}{l}\text { Intracranial } \\
\text { hemorrhage }\end{array}$ & 1.010 & 0.508 & 0.981 & 1.040 \\
\hline & Mental disorder & 1.010 & 0.417 & 0.986 & 1.036 \\
\hline \multirow[t]{4}{*}{ DBP } & $\begin{array}{l}\text { Conscious } \\
\text { disturbance }\end{array}$ & 0.989 & 0.578 & 0.951 & 1.029 \\
\hline & Epilepsy & 1.013 & 0.465 & 0.978 & 1.049 \\
\hline & $\begin{array}{l}\text { Intracranial } \\
\text { hemorrhage }\end{array}$ & 0.996 & 0.869 & 0.951 & 1.044 \\
\hline & Mental disorder & 1.008 & 0.694 & 0.970 & 1.047 \\
\hline
\end{tabular}

were not strong enough to draw a final conclusion that SBP and DBP were not correlated with the severity of CVT. NIHSS was designed to evaluate the severity of arterial stroke (12). It showed low sensitivity and specificity for CVT. For example, a CVT patient with headache and seizures was scored as 0 . The severity of the clinical presentations was currently discussed more descriptively. Yet, there was no severity evaluation scale for CVT patients based on their clinical presentations. Thus, a modified NIHSS for venous stroke is required.

SBP and DBP were found to be positively correlated with ICP. It is suggested that higher SBP and DBP would ensure the perfusion pressure in the presence of IH among CVT patients (13). It seems contradictory that SBP and DBP were positively correlated with ICP, but had no impact on the disturbance of consciousness, epilepsy, intracranial hemorrhage, and mental disorders. Except for $\mathrm{IH}$, inflammation as well as oxidative stress, apoptosis, glutamate excitotoxicity, and dysfunction of the blood-brain barrier were also involved in the pathogenesis of disturbance of consciousness, epilepsy, intracranial hemorrhage, and mental disorders (14-16). The increasing ICP level may not be the determining factor of these clinical manifestations.

TABLE 3 | Neither SBP nor ICP was correlated with mRS at 6 months of follow-up.

\begin{tabular}{lcccc}
\hline $\begin{array}{l}\text { Independent } \\
\text { variables }\end{array}$ & $\begin{array}{c}\text { Dependent } \\
\text { variables }\end{array}$ & Coeff (B) & Std Coeff ( $\beta$ ) & Significance (P) \\
\hline
\end{tabular}

$\mathrm{mRS}$ at 6 months of follow-up

\begin{tabular}{|c|c|c|c|c|}
\hline SBP & $\mathrm{mRS}$ & 0.003 & 0.010 & 0.784 \\
\hline DBP & & 0.027 & 0.016 & $0.039^{\star}$ \\
\hline ICP & & 0.015 & 0.011 & 0.159 \\
\hline
\end{tabular}

However, DBP was positively correlated with $m R S$ at 6 months of follow-up. ${ }^{\star} p<0.05$.

\section{A ROC curve of systolic blood pressure}

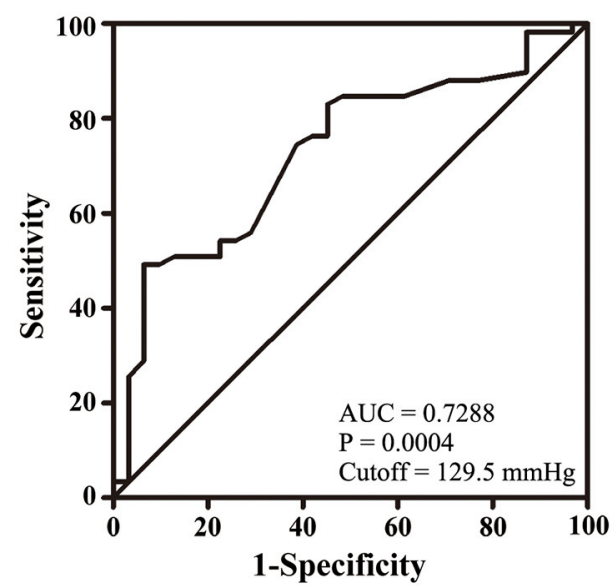

\section{B ROC curve of diastolic blood pressure}

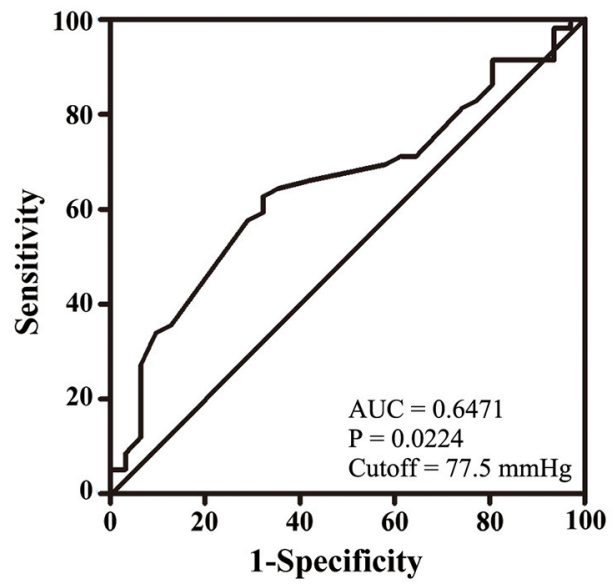

FIGURE 2 | Volumes of $129.5 \mathrm{mmHg}$ of SBP (A) and $77.5 \mathrm{mmHg}$ of DBP (B) were identified as cutoff values for IH. 
A

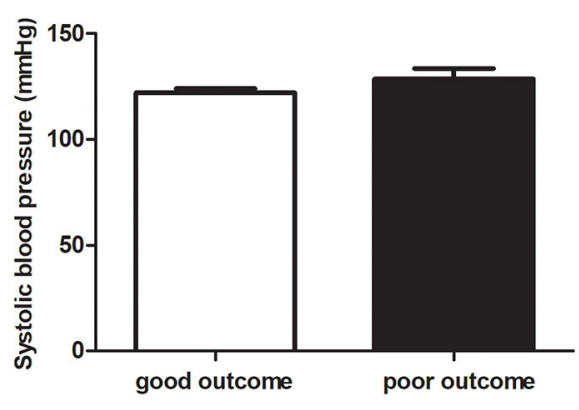

ROC curve of systolic blood pressure

C

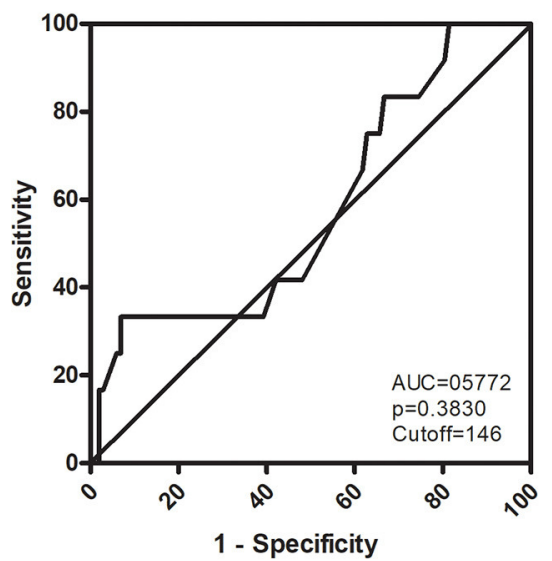

E

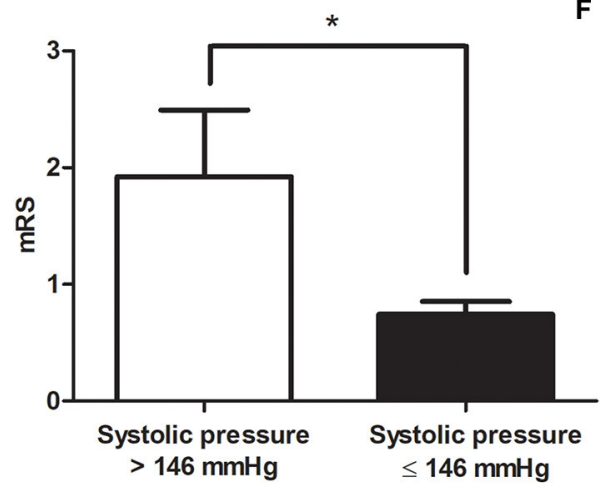

B

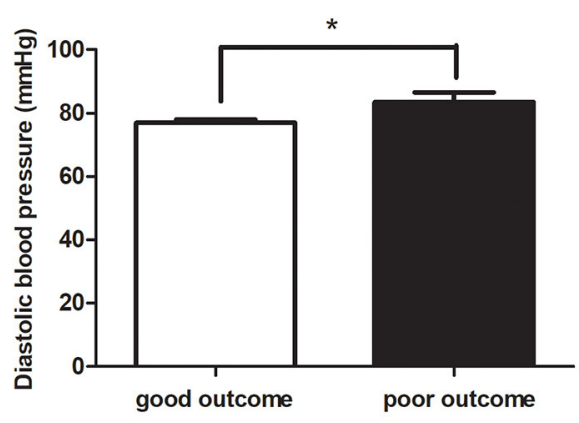

ROC curve of diastolic blood pressure

D

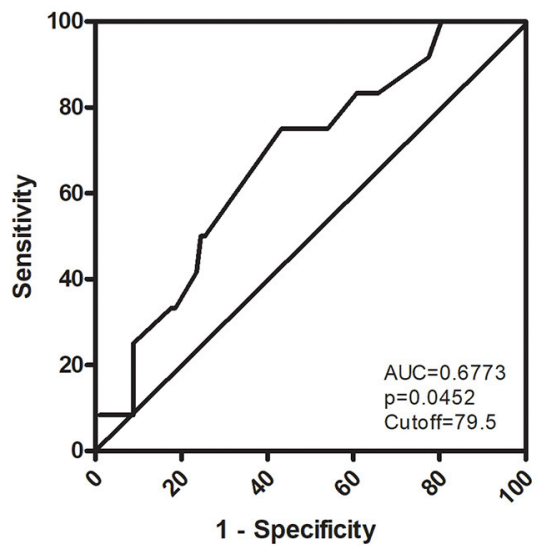

$\mathbf{F}$

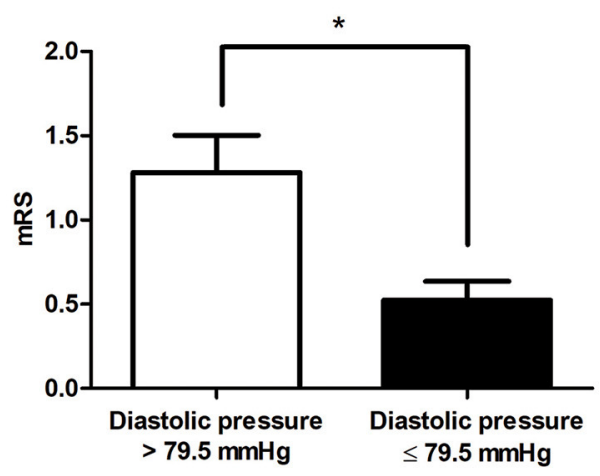

FIGURE 3 | No significant difference was found in SBP between CVT patients with good prognosis and those with poor prognosis (A). DBP in CVT patients with good prognosis was significantly lower than in those with poor prognosis (B). A volume of $146 \mathrm{mmHg}$ of SBP as a cutoff value exhibited low sensitivity and specificity (C) whereas DBP $<79.5 \mathrm{mmHg}$ predicted a good clinical outcome with high sensitivity and specificity (D). CVT patients with SBP $>146$ (E) or DBP $>79.5 \mathrm{mmHg}$ (F) had significantly higher mRS compared to those with $\mathrm{SBP} \leq 146 \mathrm{mmHg}$ (E) or $\mathrm{DBP} \leq 79.5 \mathrm{mmHg}$ (F). ${ }^{*} p<0.05$.

In a study conducted by de Bruijn et al. (17), it was reported that CVT patients with IH did not suffer from poor prognosis. Our results also indicated that ICP was not correlated with mRS at 6 months of follow-up after adjusting for SBP and DBP. Although CVT patients with SBP $>146 \mathrm{mmHg}$ had a higher rate of poor prognosis and higher mRS, a cutoff value of $146 \mathrm{mmHg}$ exhibited low sensitivity and specificity. SBP was not correlated with $\mathrm{mRS}$ at 6 months of follow-up after adjusting for ICP and SBP. A higher rate of poor prognosis and higher mRS were also observed in CVT patients with DBP $>79.5 \mathrm{mmHg}$. DBP was positively correlated with mRS at 6 months of follow-up after adjusted for SBP and ICP. DBP > $79.5 \mathrm{mmHg}$ suggested a poor prognosis with high sensitivity and specificity.

The explanations for this observation were as follows: first, increased DBP may be due to a markedly elevated ICP which results in aggravation of inflammation, oxidative stress, glutamate excitotoxicity, and dysfunction 
TABLE 4 | A higher rate of poor clinical outcome was found in CVT patients with $\mathrm{SBP}>146 \mathrm{mmHg}$ or DBP $>79.5 \mathrm{mmHg}$ compared to those with $\mathrm{SBP} \leq 146$ $\mathrm{mmHg}$ or $\mathrm{DBP} \leq 79.5 \mathrm{mmHg}$

\begin{tabular}{cccccc}
\hline & Good clinical outcome & $\begin{array}{c}\text { Poor clinical } \\
\text { outcome }\end{array}$ & Total & $\boldsymbol{P}$ \\
\hline $\mathrm{SBP} \mathrm{SBP}>146 \mathrm{mmHg}$ & 12 & 6 & 18 & $0.008^{*}$ \\
$\mathrm{SBP} \leq 146 \mathrm{mmHg}$ & 126 & 12 & 138 & \\
Total & 138 & 18 & 156 & \\
$\mathrm{DBP} \mathrm{DBP}>79.5 \mathrm{mmHg}$ & 58 & 14 & 72 & $0.005^{\star}$ \\
$\mathrm{SBP} \leq 79.5 \mathrm{mmHg}$ & 80 & 4 & 84 & \\
Total & 138 & 18 & 156 & \\
\hline
\end{tabular}

${ }^{*} p<0.05$

of the blood-brain barrier (14-16). Second, a number of studies suggested that elevated venous pressure promoted the contraction of arteriolar smooth muscle, thus increasing the peripheral vascular resistance. This may further lead to elevated $\operatorname{DBP}(18,19)$. A higher level of DBP may be correlated with an elevated central venous pressure which reduces the cerebral venous return. However, this hypothesis requires verification with further investigations.

\section{CONCLUSIONS}

Both SBP and DBP were positively correlated with ICP at admission. SBP > $129.5 \mathrm{mmHg}$ and $\mathrm{DBP}>77.5 \mathrm{mmHg}$ suggested the presence of IH in CVT patients. DBP was positively correlated with mRS at 6 months of follow-up. DBP $>79.5$ $\mathrm{mmHg}$ predicted a poor clinical outcome in CVT patients.

\section{REFERENCES}

1. Saposnik G, Barinagarrementeria F, Brown RD Jr, Bushnell CD, Cucchiara $\mathrm{B}$, Cushman $\mathrm{M}$, et al. Diagnosis and management of cerebral venous thrombosis: a statement for healthcare professionals from the American Heart Association/American Stroke Association. Stroke. (2011) 42:115892. doi: 10.1161/STR.0b013e31820a8364

2. Luo Y, Tian X, Wang X. Diagnosis and treatment of cerebral venous thrombosis: a review. Front Aging Neurosci. (2018) 10:2. doi: 10.3389/fnagi.2018.00002

3. Devasagayam S, Wyatt B, Leyden J, Kleinig T. Cerebral venous sinus thrombosis incidence is higher than previously thought: a retrospective population-based study. Stroke. (2016) 47:21802. doi: 10.1161/STROKEAHA.116.013617

4. Capecchi M, Abbattista M, Martinelli I. Cerebral venous sinus thrombosis. J Thromb Haemost. (2018) 16:1918-31. doi: 10.1111/jth.14210

5. Ferro JM, Canhao P, Stam J, Bousser MG, Barinagarrementeria F, Investigators I. Prognosis of cerebral vein and dural sinus thrombosis: results of the International Study on Cerebral Vein and Dural Sinus Thrombosis (ISCVT). Stroke. (2004) 35:664-70. doi: 10.1161/01.STR.0000117571.76197.26

6. Kowoll CM, Kaminski J, Weiss V, Bosel J, Dietrich W, Juttler E, et al. Severe cerebral venous and sinus thrombosis: clinical course, imaging correlates, and prognosis. Neurocrit Care. (2016) 25:392-9. doi: 10.1007/s12028-0160256-8

7. Duman T, Uluduz D, Midi I, Bektas H, Kablan Y, Goksel BK, et al. A multicenter study of 1144 patients with cerebral venous

\section{DATA AVAILABILITY STATEMENT}

The raw data supporting the conclusions of this article will be made available by the authors, without undue reservation.

\section{ETHICS STATEMENT}

The studies involving human participants were reviewed and approved by the ethics board of Xuanwu Hospital. Written informed consent to participate in this study was provided by the participants' legal guardian/next of kin.

\section{AUTHOR CONTRIBUTIONS}

ML: contributed to study design and drafting the manuscript. LP: contributed to study design and data collection. XG: contributed to data analysis. JH: contributed to data collection. RM: contributed to acquisition of study funding, study design, and critical revision of the manuscript. XJ: contributed to data interpretation and critical revision of the manuscript. All authors contributed to the article and approved the submitted version.

\section{FUNDING}

This study was supported by the National Key R\&D Program (2017YFC1308401), the National Natural Science Foundation (81371289) and the Project of Beijing Municipal Top Talent of Healthy Work of China. This study was also funded by the Natural Science Foundation of Beijing Municipality (7212047). The grant number of Project of Beijing Municipal Top Talent of Healthy Work is 2014-2-015.

thrombosis: the VENOST study. I Stroke Cerebrovasc Dis. (2017) 26:1848-57. doi: 10.1016/j.jstrokecerebrovasdis.2017.04.020

8. Wajngarten M, Silva GS. Hypertension and stroke: update on treatment. Eur Cardiol. (2019) 14:111-5. doi: 10.15420/ecr.2019.11.1

9. Favoni V, Pierangeli G, Toni F, Cirillo L, La Morgia C, Abu-Rumeileh $\mathrm{S}$, et al. Idiopathic Intracranial Hypertension Without Papilledema (IIHWOP) in chronic refractory headache. Front Neurol. (2018) 9:503. doi: 10.3389/fneur.2018.00503

10. Breteau G, Mounier-Vehier F, Godefroy O, Gauvrit JY, MackowiakCordoliani MA, Girot M, et al. Cerebral venous thrombosis 3-year clinical outcome in 55 consecutive patients. J Neurol. (2003) 250:2935. doi: 10.1007/s00415-003-0932-4

11. Mehta A, Danesh J, Kuruvilla D. Cerebral venous thrombosis headache. Curr Pain Headache Rep. (2019) 23:47. doi: 10.1007/s11916-019-0786-9

12. Fischer U, Arnold M, Nedeltchev K, Brekenfeld C, Ballinari P, Remonda L, et al. NIHSS score and arteriographic findings in acute ischemic stroke. Stroke. (2005) 36:2121-5. doi: 10.1161/01.STR.0000182099.04994.fc

13. Depreitere B, Meyfroidt G, Guiza F. What do we mean by cerebral perfusion pressure? Acta Neurochir Suppl. (2018) 126:201-3. doi: 10.1007/978-3-319-65798-1_41

14. Tiwari HS, Misra UK, Kalita J, Mishra A, Shukla S. Oxidative stress and glutamate excitotoxicity contribute to apoptosis in cerebral venous sinus thrombosis. Neurochem Int. (2016) 100:91-6. doi: 10.1016/j.neuint.2016.09.003

15. Rashad S, Niizuma K, Sato-Maeda M, Fujimura M, Mansour A, Endo H, et al. Early BBB breakdown and subacute inflammasome activation and 
pyroptosis as a result of cerebral venous thrombosis. Brain Res. (2018) 1699:54-68. doi: 10.1016/j.brainres.2018.06.029

16. Wang L, Duan J, Bian T, Meng R, Wu L, Zhang Z, et al. Inflammation is correlated with severity and outcome of cerebral venous thrombosis. J Neuroinflammation. (2018) 15:329. doi: 10.1186/s12974-0181369-0

17. de Bruijn SF, de Haan RJ, Stam J. Clinical features and prognostic factors of cerebral venous sinus thrombosis in a prospective series of 59 patients. for the cerebral venous sinus thrombosis study group. J Neurol Neurosurg Psychiatry. (2001) 70:105-8. doi: 10.1136/jnnp.70.1.105

18. Iida N, Mitamura Y. Effects of venous pressure elevation on myogenic vasoconstrictive responses to static and dynamic arterial pressures. Jpn J Physiol. (1989) 39:811-23. doi: 10.2170/jjphysiol.39.811

19. Strandberg TE, Pitkala K. What is the most important component of blood pressure: systolic, diastolic or pulse pressure? Curr Opin Nephrol Hypertens. (2003) 12:293-7. doi: 10.1097/00041552-20030500000011
Conflict of Interest: The authors declare that the research was conducted in the absence of any commercial or financial relationships that could be construed as a potential conflict of interest.

Publisher's Note: All claims expressed in this article are solely those of the authors and do not necessarily represent those of their affiliated organizations, or those of the publisher, the editors and the reviewers. Any product that may be evaluated in this article, or claim that may be made by its manufacturer, is not guaranteed or endorsed by the publisher.

Copyright (C) 2021 Li, Pan, Gao, Hou, Meng and Ji. This is an open-access article distributed under the terms of the Creative Commons Attribution License (CC BY). The use, distribution or reproduction in other forums is permitted, provided the original author(s) and the copyright owner(s) are credited and that the original publication in this journal is cited, in accordance with accepted academic practice. No use, distribution or reproduction is permitted which does not comply with these terms. 